\title{
RESULTS OF LABORATORY STUDIES OF DEVICE FOR TRANSPORTING HEADS TO THE ELEVATOR OF CABBAGE HARVEST MACHINE
}

\author{
Nina Toncheva ${ }^{1}$, Andrei Samsonov ${ }^{1}$, Vitaly Yegorov $^{1}$, Valeriy Lebedev ${ }^{2}$ \\ ${ }^{1}$ Chuvash State Pedagogical University. I. Y. Yakovlev, Russian; \\ ${ }^{2}$ Chuvash State Agricultural Academy, Russian \\ toncheva01@yandex.ru,dyha2004@mail.ru,evp121@mail.ru, lebed1906.v@mail.ru
}

\begin{abstract}
The reliability of the workflow of cabbage harvest machines to a large extent depends on the sustainability of the transportation of cabbage from the cutting zone to the elevator. When the process of transportation of cabbages in the specified location is interrupted, the cutting apparatus of the machine is clogged. This problem can be solved by using a transporting device, consisting of clamping the blade and mounted in opposition to the eccentric-crank shaft of the active tray. The front ends of the plates of the active tray plates are provided with guide grooves and are mounted on a common traverse with the ability to perform oscillatory motion. The results of the laboratory studies of the device for transportation of heads of the cutting apparatus to the elevator of the cabbage harvest machine are presented in this article. Optimization of the parameters of the device for transportation of cabbage from the cutting zone to the elevator was performed by the method of experiment planning. When planning the following factors are taken into account: the angular velocity $\omega$ of the eccentric-crank shaft of the conveying device, the clearance $\Delta$ between the blade clamping and transporting conveyor device and the working speed $v$ of the cabbage harvest machine. The optimal values of the device for transportation of the head: angular velocity $\omega$ of the eccentric-crank shaft of the conveying device was $0,105 \mathrm{rad} / \mathrm{s}$, the clearance $\Delta$ between the blade clamping conveyor and conveying device $60 \ldots 70 \mathrm{~mm}$, the working speed $v$ of the cabbage harvest machine are defined. The operating speed $\mathrm{v}$ of the cabbage harvest machine is turned out to be insignificant.
\end{abstract}

Keywords: cabbage harvest machine, cutting machine, conveying device.

\section{Introduction}

The development of the designs of the cutting apparatus of cabbage harvesters is inextricably linked with its technological process of mechanized cutting of cabbage, which provides for the lifting of dead cabbage plants, their alignment with respect to the cutting plane, the separation of heads from the stumps and the continuous transportation of heads from the cutting zone to the elevator of the cabbage harvesting machine. These operations must be performed consistently and continuously. The reliability of the cutting device working process largely depends on the stability of transportation of cabbages from the cutting area to the elevator of the cabbage harvesting machine. When the process of transporting the heads to the specified location is interrupted, the cutting machine of the cabbage harvesting machine is clogged. In this context, many researchers were particularly interested in the process. They proposed various technical solutions and investigated a variety of device designs for transporting heads from the cutting zone to the unloading elevator [1-6]. However, the known devices do not fully provide the stability of transporting the heads from the cutting zone to the elevator of the cabbage harvesting machine.

The purpose of this work is to study and determine the basic parameters of the device for transporting heads from the cutting zone to the elevator of a cabbage harvesting machine that provides the stability of the technological process.

\section{Materials and methods}

This problem can be solved by the use of the transporter shown in Fig. 1 [7]. The transporting device consists of clamping the blade (not shown) and inserts the active tray installed out of phase on the eccentric-crank shaft (EQ). The front ends of the active tray plates are provided with guide grooves and are mounted on a common traverse with the ability to perform oscillatory motion.

The workflow is as follows. In the area of the blades, the heads are separated from the stumps and fed into the gap between the elastic blade clamping conveyor and the active tray plates, committing reciprocating circular motions in a longitudinal vertical plane. The heads are based on the plates, which travel in a given time in the flow direction, as the tray plates, moving at this time against the flow, are further away from the cloth presser device. This impact of the tray to the heads is achieved in that way that the tray moves in the flow direction in the upper part of the trajectory, and the reverse is 
made on the bottom. In the combined action of the clamping conveyor and the active tray cabbages move to the receiving part of the elevator.

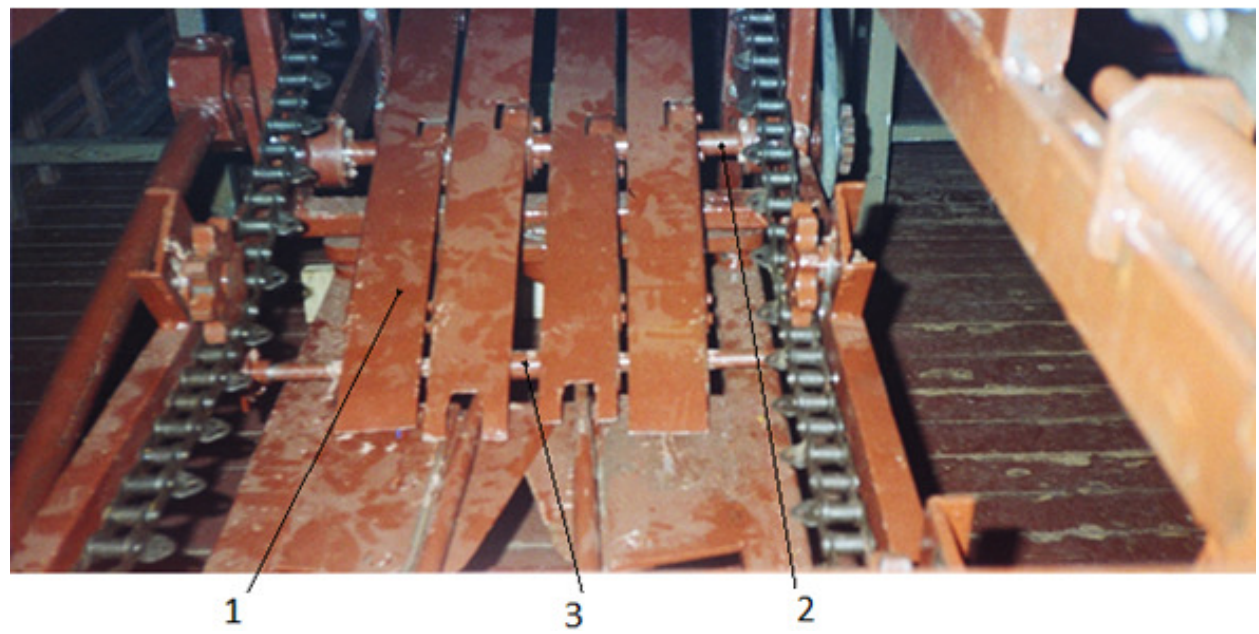

Fig. 1. General view of the transporter of the cabbage harvest machine:

1 - plate active tray; 2 - eccentric-crank shaft (EQ); 3 - traverse

The efficiency of the head transportation in this device depends on many factors. The main of them are the clearance between the clamping conveyor blade and the active tray, the angular velocity of rotation EQ, the radius of the eccentrics, the working speed of the machine etc. These factors can be optimized experimentally.

In order to determine the optimal parameters and operating conditions, a cutting device with an active transport device was examined on a laboratory bench (Fig. 2). The stand consists of guide rails and a frame, on which a cutting device with an active transport device is hung by means of a bracket and a chain. A platform with clamps for fixing cabbage plants is moved along the guide rails, driven by an electric motor through a cylindrical gearbox. The cutting device is driven by a geared motor. The movable platform of the stand was fixed in the clamps of the head with an outer stump.

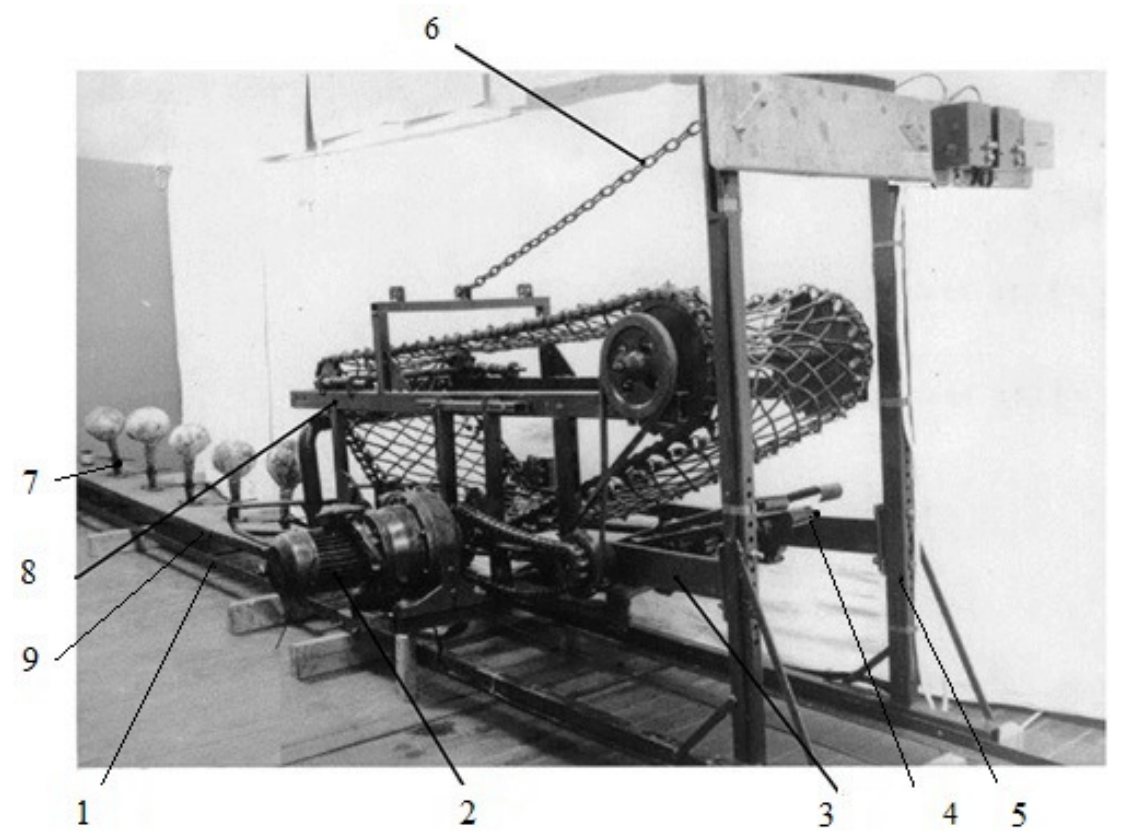

Fig. 2. General view of the laboratory stand: 1 - guide rails; 2 - motor-reducer; 3 - bracket; 4 - active transporting device; 5 - frame; 6 - chain; 7 - clamps; 8 - cutting device; 9 - platform

During the working period, a platform filled with cabbages was fed to the cutting device at speeds corresponding to the working speeds of the cabbage harvesting machine. As the platform moved, the heads were cut and transported in a shearing machine. After leaving the apparatus, they were placed 
on a platform, which at that time was already in the unloading zone. The efficiency of the transport process was estimated by the time of the stay of the heads in the shearing apparatus after separation from the stumps. During each implementation of the experiment, the stability of the process in the cutting device was evaluated indirectly by the time of transportation of the head with the active tray.

The experiments were carried out in triplicates according to the scheme of full factorial experiment. For the experiments the cabbage varieties Glory 1305 and Snow White were used. In laboratory studies a full factorial experiment on the scheme of orthogonal central composite designs was conducted to optimize the time of transportation of the heads by the active tray.

For the main factors determining the efficiency of the process of cabbage transportation the angular velocity $\omega$ of rotation of the EQ, the size of the gap $\Delta$ between the blade clamping conveyor and the active pan in the area of the cross member (here, the gap is not being changed during the experiment) and the speed $v$ feed to the working platform cutting apparatus that simulates the working speed of the cabbage harvest machine were taken. Intervals and the variation levels of the factors based on the theoretical studies were chosen (Table 1).

Table 1

Intervals and the variation levels

\begin{tabular}{|c|c|c|c|c|c|c|c|c|}
\hline \multirow{3}{*}{ 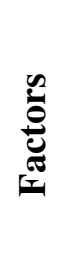 } & \multirow{3}{*}{ 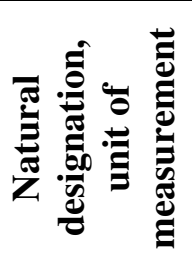 } & \multicolumn{2}{|c|}{$\begin{array}{l}\text { Main } \\
\text { level }\end{array}$} & $\begin{array}{l}\text { Range of } \\
\text { variation }\end{array}$ & \multicolumn{2}{|c|}{ Top level } & \multicolumn{2}{|c|}{ Lower level } \\
\hline & & \multicolumn{7}{|c|}{ value } \\
\hline & & natural & coded & natural & natural & coded & natural & coded \\
\hline$x_{1}$ & $\omega, \mathrm{rad} \cdot \mathrm{s}^{-1}$ & 0.11 & 0 & 0.05 & 0.16 & +1 & 0.06 & -1 \\
\hline$x_{2}$ & $\Delta, \mathrm{mm}$ & 67.5 & 0 & 32.5 & 100 & +1 & 35 & -1 \\
\hline$x_{3}$ & $v, \mathrm{~m} \cdot \mathrm{s}^{-1}$ & 1.17 & 0 & 0.38 & 1.55 & +1 & 0.78 & -1 \\
\hline
\end{tabular}

\section{Results and discussion}

The experimental data were approximated by the regression equation

$$
y=2.929+0.225 x_{1}+0.857 x_{2} x_{3}+1.102 x_{1}^{2}-0.763 x_{2}^{2}+0.729 x_{3}^{2} .
$$

The test showed that the mathematical model (1) is adequate at $5 \%$ significance level. This allows concluding that computed according to the equation the y value differs from the experimental by an amount not exceeding the error of the experiments.

For in-depth study of the nature and extent of the factor influence on the process at the time of cutting cabbages in the apparatus after separation from the stumps two-dimensional cross-sections of response surface for $\omega=0.11 \mathrm{rad} \cdot \mathrm{s}^{-1}, \Delta=67.5 \mathrm{~mm}, v=1.17 \mathrm{~m} \cdot \mathrm{s}^{-1}$ were built (Fig. 3).

Within these limits, the factors affecting the stability of the transportation of the heads from the cutting zone to the elevator of the cabbage harvesting machine are most affected by the angular velocity $\omega$ of the rotation of the ECB and the gap $\Delta$ between the presser and the active tray. Less significant in the experiments was the translational velocity $v$ of the motion of the platform. It follows that the experimental conveying device reacts poorly to changes in the working speed of the cabbage harvesting machine. This is its advantage. With an increase in the angular velocity $\omega$ of the rotation of the ECB and a decrease in the gap $\Delta$ between the presser and the active tray from 100 to $67.5 \mathrm{~mm}$, the residence time of the heads in the shearing apparatus after separation from the bobbins decreases (Fig. 3, a and b). By further change in the gap $\Delta$, the time of stay of the heads in the shearing apparatus after separation from the sticks increases again, i.e. the transportation process proceeds more efficiently with the average values of the angular velocity $\omega$ of the rotation of the ECB and the clearance $\Delta$ between the presser and the active tray. This is explained by the fact that the heads are more often exposed to the action of the active trays, they are optimally fixed by the presser belt during the joint action with the active tray. At small values of the gap $\Delta$ between the presser and the active tray, the heads lose their fixation and roll back, and for very small values, due to excessive fixation, the effect of the active trays in the direction of the flow decreases. 
a)

Function Plot (NEW.STA 11v*20c)

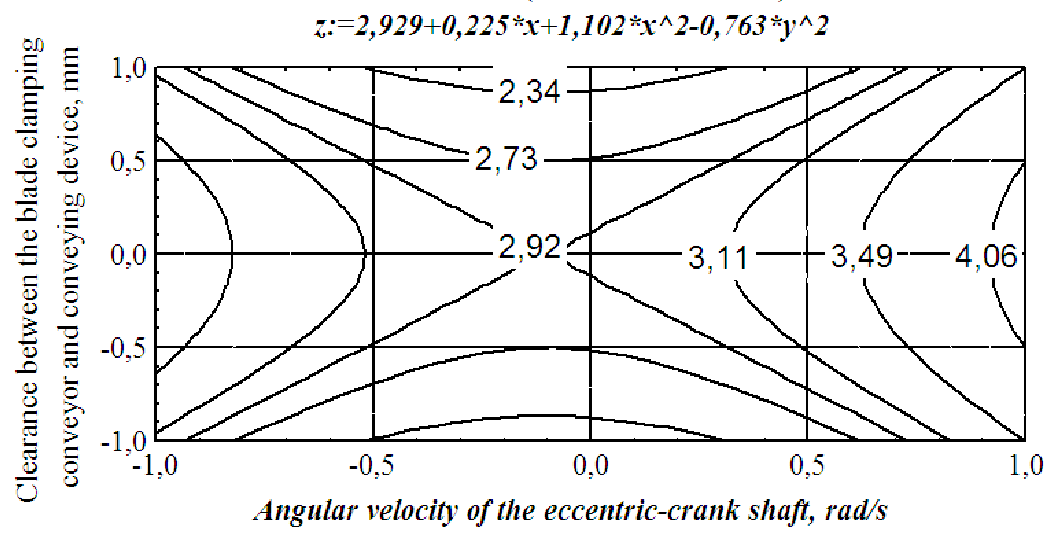

b)

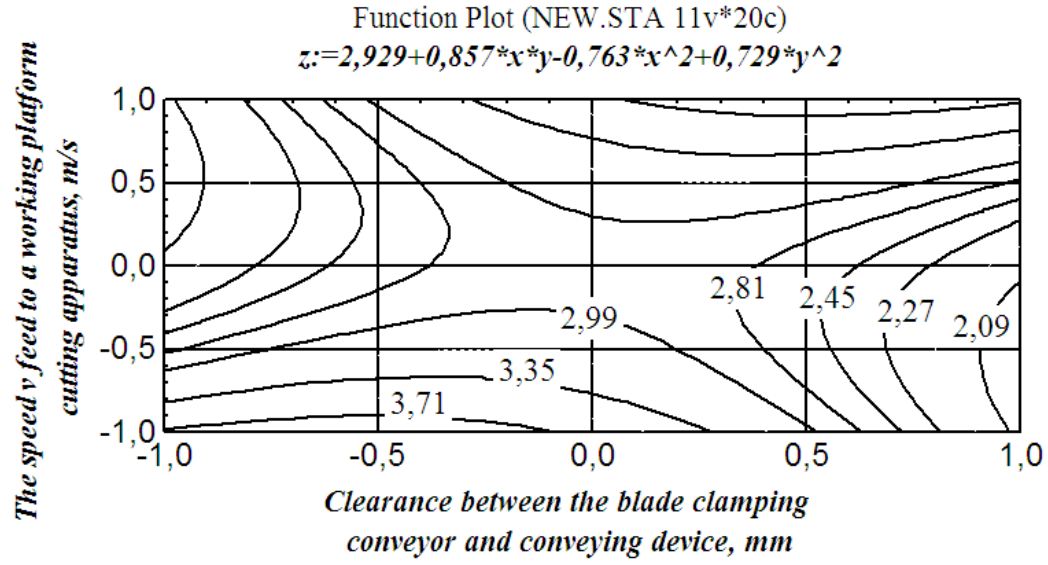

c)

Function Plot (NEW.STA $11 \mathrm{v} * 20 \mathrm{c})$

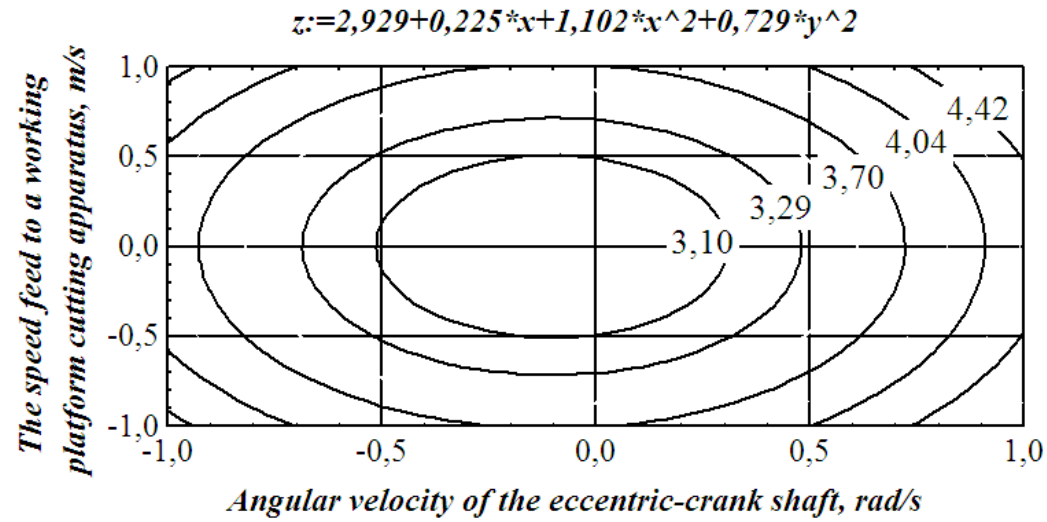

Fig. 3. Dependence of residence time of the heads in the shear apparatus after separation of the stumps on the angular velocity $\omega$ of rotation of $\mathrm{EQ}$, the clearance $\Delta$ between the blade clamping conveyor and the active tray and the speed $v$ flow platform to the working cutting apparatus:

$$
\mathrm{a}-\text { at } v=1.17 \mathrm{~m} \cdot \mathrm{s}^{-1} ; \mathrm{b}-\text { at } \omega=0.11 \mathrm{rad} \cdot \mathrm{s}^{-1} ; \mathrm{c}-\text { for } \Delta=67.5 \mathrm{~mm}
$$

The system of differential equations was made to determine the values of the factors providing the highest efficiency of the conveying device.

$$
\begin{aligned}
& \frac{d y}{d x_{1}}=0.23+2.2 x_{1} \\
& \frac{d y}{d x_{2}}=0.59-1.52 x_{2} \\
& \frac{d y}{d x_{3}}=0.59+1.46 x_{3}
\end{aligned}
$$


The optimal values of the factors providing the greatest efficiency of the transportation process of cabbages from the cutting zone to the elevator of the cabbage harvest machine were determined after equating the partial derivatives to zero and solving the system of equations relative to the unknown. In coded form the optimal parameters are equal to the following values: $x_{1}=-0.10, x_{2}=0, x_{3}=0$, by passing to the natural values, we get the angular velocity of rotation EQ $\omega=0.105 \mathrm{rad} \cdot \mathrm{s}^{-1}$; the gap between the clamping conveyor and the active tray, $\Delta=67.5 \mathrm{~mm}$; the translational velocity of the platform $v=1.17 \mathrm{~m} \cdot \mathrm{s}^{-1}$.

Analysis of the cutting apparatus work with the active tray showed the stability of the technological process of transportation. The stability of the technological process of transportation of the cutting apparatus with the improved conveying device is ensured by the permanent contact of the head with the plates and the tray, reliable fixation of the head cloth presser conveyor in the process of joint action with the plates of the tray, which leads to the exclusion of downloading cabbages on the transporting device, and as a result, eliminates the clogging of the cutting apparatus. It should be noted that for large clearances $\Delta$ small cabbages lose their hold and slip back, and at very small values the effect of the plates of the tray in the direction of the flow reduces due to the excessively rigid fixation.

\section{Conclusions}

Taking the above mentioned into account, it is recommended to accept the gap between the web and the active clamping conveyor tray $\Delta=60-70 \mathrm{~mm}$ at harvesting cabbage with cabbage heads of small and medium-sized, and when cleaning large heads of cabbage $-70 \mathrm{~mm}$ or more, the rate of translational motion of the platform supply $-1.17 \mathrm{~m} \cdot \mathrm{s}^{-1}$. The angular velocity of rotation $\omega=0.105 \mathrm{rad} \cdot \mathrm{s}^{-1}$, which is optimal in terms of efficient transport of heads cut after the active tray should be left unchanged, since it also fully satisfies the conditions of high-quality cutting of heads.

\section{References}

1. Вольф А.И. Как модернизировать машину УКМ-2 (How to upgrade the machine UKM-2). Potatoes and vegetables, 1992, No 4, pp. 9-11 (in Russian).

2. Кацанов С.Г., Тихонов Н.И. Модернизированный капустоуборочный комбайн (Upgraded kapustouborochny harvester). Mechanization and electrification of agriculture, 1993, No 9, pp. 13-14 (in Russian).

3. Костюченков Н.В. Совершенствование работы срезающего аппарата капустоуборочной машины (Improving the work of chopping apparatus of cabbage harvest machine). Extended abstract of candidate thesis. Chelyabinsk. 1999 (in Russian).

4. Тихонов Н.И. Однорядный капустоуборочный комбайн (Cabbage harvest single-row harvester). Potatoes and vegetables, 1984, No 9, pp. 5-14 (in Russian).

5. Тихонов Н.И. Транспортирующее устройство к срезающему аппарату капустоуборочных машин (Transporting the device to the chopping apparatus of cabbage harvest machines). Tractors and agricultural machines, 1983, No 5, pp. 15-18 (in Russian).

6. Чарушников В.А. Новая капустоуборочная машина (New cabbage harvest machine). Mechanization and electrification of agriculture, 1995, No 7, pp. 16-17 (in Russian).

7. Тончева Н.Н. Капустоуборочная машина для крестьянских (фермерских) хозяйств (Сabbage harvest machine for farms). Vestnik of Kursk state agricultural Academy, 2012, No 4, pp. 70-71 (in Russian). 